\title{
Mechanistic influence of chemical agglomeration agents on removal of inhalable particles from coal combustion
}

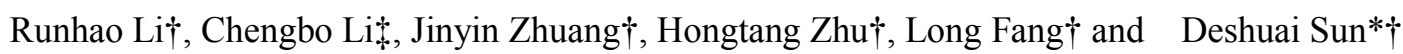

$\uparrow$ College of Chemistry and Chemical Engineering, Qing dao University, Qingdao 266071, China

\$ Qingdao Elevator Safety Emergency and Monitoring Center, Qingdao 266071, China

5 Pages, 3 figures and 1 tables 


\section{Tables}

Table S1. Basic properties of fly ash.

\begin{tabular}{llll}
\hline Median diameter $(\mu \mathrm{m})$ & Density $\left(\mathrm{kg} / \mathrm{m}^{3}\right)$ & Moisture content $(\%)$ & Loss on ignition $(\%)$ \\
\hline 14.36 & 1838 & 0.78 & 3.81 \\
\hline
\end{tabular}




\section{Figures}

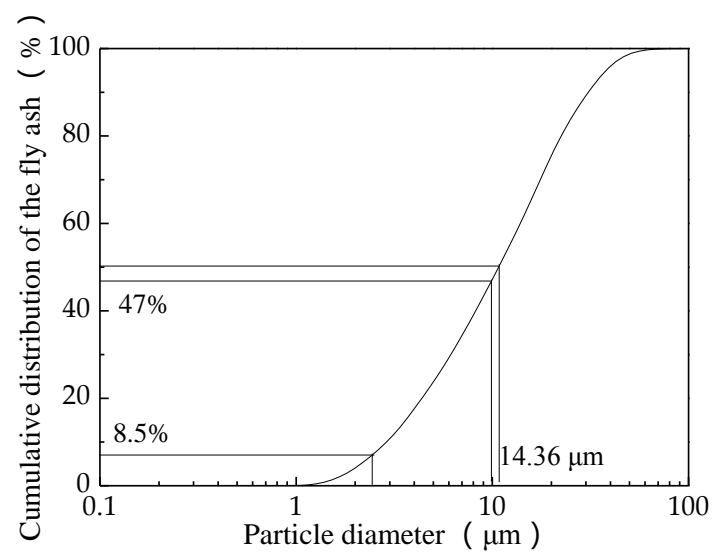

Figure S1. The initial size distribution of the fly ash. 


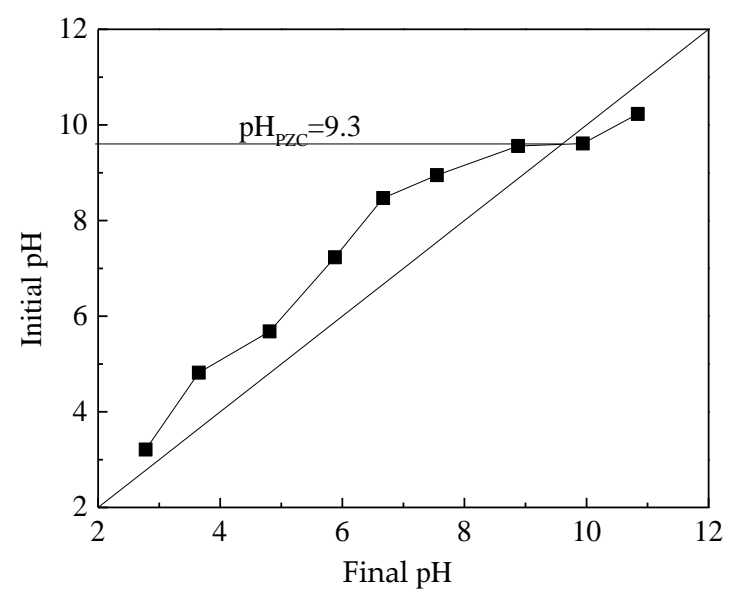

Figure. S2. pHpzc of fly ash particles 


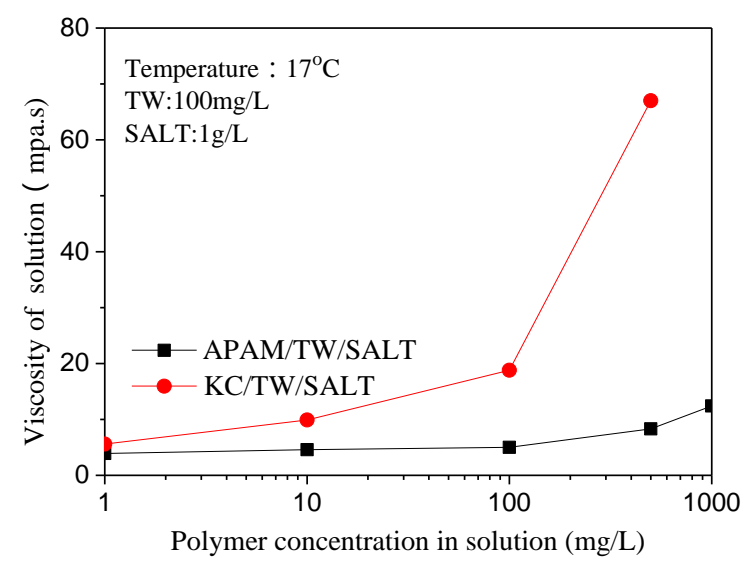

Figure. S3. Viscosity of chemical agglomeration solution 